\title{
NOTAS SOBRE A DUALIDADE ENTRE "ALTA" E "BAIXA" CULTURAS NO CAMPO CULTURAL BRASILEIRO
}

\author{
Maria Eduarda da Mota Rocha*
}

\begin{abstract}
Resumo: O texto propõe uma reflexão ensaística sobre a dualidade entre "alta" e "baixa" culturas no Brasil, traçando linhas muito gerais da formação do campo cultural e da consagração de um cânone modernista no interior deste campo. Por fim, discute de que maneira a ascensão de uma nova geração de artistas e intelectuais a partir da década de 1980 bem como a inclinação mais recente das políticas culturais em direção a uma concepção "antropológica" de cultura tem assumido a forma de uma contestação mais aberta àquele cânone.
\end{abstract}

Palavras-chave: Cultura brasileira, cultura erudita, cultura popular, cultura de massas

Abstract: The text proposes an essay on the duality between "high" and "low" culture in Brazil, pointing some aspects of the rising of the cultural field and the consecration of a modernist canon within this field. Finally, it discusses how the rise of a new generation of artists and intellectuals from the 1980s as well as the inclination of the latest cultural policies toward an "anthropological" conception of culture has taken the form of a dispute over that canon.

Keywords: Brazilian culture, high culture, popular culture, mass culture.

\footnotetext{
* Doutora em Sociologia pela Universidade de São Paulo (USP). Atualmente é Professora do Departamento e da Pós-Graduação em Sociologia da Universidade Federal de Pernambuco (UFPE). É autora de $A$ nova retórica do capital: a publicidade brasileira em tempos neoliberais. São Paulo: Edusp, 2010. E-mail: me.rocha@uol.com.br.
} 
$\mid 46$ |

Notas sobre a dualidade entre...

A modernidade assistiu ao surgimento das categorias "erudito" e "popular" como trincheiras simbólicas que serviram, durante muito tempo, para diferenciar a produção cultural consagrada daquela incapaz de dotar os seus consumidores dos signos de distinção tão preciosos em uma sociedade de crescente mobilidade e anonimato. Bourdieu (1982 e 2007) analisou a formação do campo cultural e a maneira como o capital simbólico atrelado às obras consagradas no interior deste campo atuava na produção e reprodução das desigualdades sociais, funcionando como um marcador poderoso de classe ao distinguir os consumidores da "alta cultura" dos demais mortais comuns.

Ao longo do século XIX, a "alta cultura" serviu para distinguir os burgueses e os segmentos ilustrados das classes médias daqueles mais recém-chegados às disputas por riqueza, prestígio e poder nas cidades, que cresciam ao ponto de tornar pouco eficazes mecanismos mais antigos de distinção social, como o nome de família ou mesmo o capital econômico em estado puro. Isto significou a difusão de categorias mais rígidas de classificação da cultura e a imposição de uma distância maior entre a produção erudita e popular, em termos do prestígio alcançado por cada uma delas. O surgimento de instâncias de consagração, como museus, academias, galerias e revistas, reforçou as fronteiras entre os diferentes tipos de produção, atenuando a intensa circularidade cultural que havia caracterizado a Idade Média (BAKTHIN, 2008; GINZBURG, 1987).

Por outro lado, paralelamente à constituição do campo de produção erudita, tevelugar um processo de "nivelamento cultural" que forjou um novo espaço de produção e consumo de formas simbólicas, constituído em função de um público consumidor emergente identificado como classe média (COHN, 1973, p. 55). Este universo cultural, em formação na Europa desde pelo menos o século XVIII, foi estendendo suas fronteiras e ocupando espaços até então destinados às culturas populares ou à produção cultural voltada à elite cortesã. $\mathrm{O}$ resultado foi um novo compromisso entre as camadas populares e a burguesia tornada elite hegemônica. Barbero (1987, p. 134) identifica o mesmo processo através do qual 
a cultura de massa veio a ser este âmbito de integração das classes inferiores à sociedade urbano-industrial, integração esta mais simbólica do que propriamente material ou política. Não se trata da aniquilação de matrizes culturais populares ou mesmo eruditas, mas de seu redirecionamento rumo à composição da hegemonia burguesa. Esta hegemonia pautou-se fortemente na integração das camadas populares ao mercado de bens materiais e simbólicos, adensando aquele público identificado por Cohn. Porém, ao mesmo tempo em que crescia um mercado cultural voltado ao grande público, no campo de produção erudita, as fronteiras entre a "alta" e a "baixa" cultura eram estabelecidas e legitimadas em um grau sem precedentes.

No Brasil, os processos de formação do campo cultural e da cultura de massas foram mediados pela própria condição colonial e seus desdobramentos. Os três primeiros séculos de colonização assistiram ao que Celso Furtado (1984) chamou de "síntese barroca", o predomínio da cultura católica nas áreas em que brancos organizavam a vida social no sentido da produção para exportação. Ali, também os negros, índios e mestiços estavam submetidos ao catolicismo e, neste sentido, tanto dominantes quanto dominados sofriam a influência de uma visão católica de mundo, estando mais próximos do ponto de vista dos valores, crenças e ritos partilhados, apesar das práticas sincréticas e heterodoxas que aconteciam nas bordas da grande propriedade. Ainda segundo Furtado, somente após a Revolução Industrial, com a mudança no papel do Brasil na divisão internacional do trabalho, as elites locais voltaram-se mais decisivamente para os centros da cultura europeia, de onde brotavam tanto os fluxos de bens de consumo quanto as correntes burguesas de pensamento. Aconteceu, então, o que ele chamou de "ruptura pós-barroco", a diferenciação crescente entre as visões de mundo das elites ilustradas, sob influência do racionalismo e do romantismo, e aquelas do restante da população, que continuavam seu processo formativo a partir das matrizes católicas, indígenas e africanas.

A diferenciação entre cultura das elites e culturas populares ganhou forma decisiva a partir da segunda metade do século 
|48 |

Notas sobre a dualidade entre...

XVIII, com o arcadismo e o neoclassicismo que abrigaram, pela primeira vez na colônia, "conjuntos orgânicos de homens de letras" já preocupados com o problema da formação da literatura brasileira (CANDIDO, 1981, p. 25 e ss.), com a consagração de uma tradição literária que instituísse algum nível de continuidade entre as obras e entre os autores. Com a Independência, a literatura teve que se empenhar mais ainda na construção nacional e este foi o propósito que guiou o romantismo na direção das culturas populares em busca de símbolos da identidade brasileira. Identificando os traços de uma teoria da literatura presente neste movimento, Antonio Candido (1981, p. 328 e ss) aponta o reconhecimento dos índios como quintessência da identidade nacional. A natureza, os costumes e a religião também foram temas centrais para o romantismo literário no Brasil.

A conversão dos costumes nacionais em tema literário implicava um olhar mais atento para as camadas populares, mas a fixação na figura do índio como emblema da nacionalidade pura limitava o alcance desta visada. Além disso, o tratamento literário se restringia à sua transformação em tema privilegiado, com pouca repercussão no plano da forma. Para os propósitos deste texto, interessa destacar que, mesmo na ausência de um campo literário estruturado, a assimetria de poder entre um grupo de intelectuais encarregados de dar forma à "cultura brasileira" e o resto da população confinado na figura de um "povo" já se manifestava. Tanto mais porque a própria literatura foi se consagrando como forma cultural por excelência, e os recursos para a expressão literária estavam concentrados nas mãos de uma intelectualidade formada de filhos de famílias ricas do campo que iam se instruir em São Paulo, Recife e Rio de Janeiro, somados aos filhos de comerciantes luso-brasileiros e de profissionais liberais, com raros casos de escritores de origem pobre (BOSI, 1982, p. 99).

A dualidade entre cultura erudita e popular mudou de significado a partir da institucionalização de um cânone modernista, nas décadas de 1920 e 1930, na medida em que as culturas populares deixavam de ser consideradas apenas como tema e passavam a contar também como fonte de recursos para 
inovações no plano da forma. O marco principal deste processo foi, sem dúvida, a Semana de Arte Moderna realizada em 1922, embora os processos que criaram as condições materiais e políticas do modernismo paulista já tivessem em curso há algum tempo (MICELI, 2003). Na primeira geração de modernistas, o primitivismo, que na Europa significava a fuga do familiar ao exótico, foi ressignificado como a busca pelas raízes de uma cultura nacional em formação, o que conferiu às culturas populares um lugar destacado (CANDIDO, 1965). Deste modo, as linguagens das vanguardas europeias mais cosmopolitas eram postas a serviço do projeto de construção nacional, que passava a ser, juntamente com o primado da inovação formal, um traço forte do modernismo brasileiro a se prolongar nas gerações seguintes, apesar das divergências tanto no interior de cada geração quanto entre elas. Em meio às tensões entre cosmopolitismo e localismo que, segundo Candido (1965, p. 45), caracterizam a vida cultural brasileira, o foco na identidade nacional tornou-se o eixo da conversão do modernismo em projeto ideológico nos anos 1930, para além da sua dimensão propriamente estética. Isso ficou particularmente visível na crescente preocupação de registro das manifestações populares com vistas à pesquisa das raízes da cultura brasileira e na sua dignificação a partir deste propósito (LAFETÁ et al., 2000), de maneira que, cada vez mais, era a produção urbana e comercial que passava a preencher a categoria de "baixa cultura".

Neste contexto, o nacionalismo contribuiu para legitimar e pôr em diálogo o erudito e o popular, ao fazer deste último a reserva de brasilidade e a matéria-prima para as experimentações de artistas modernistas em busca da forma adequada ao "conteúdo nacional". Mas as trocas efetivas entre as formas populares e eruditas de cultura não impediram que estas produções fossem categorizadas como tipos essencialmente diferentes, o primeiro, voltado à inovação formal, o outro, engessado na tradição, sob crescente domínio do folclorismo.

Ao tratar da vida cultural da cidade de São Paulo na década de 1950, Maria Arminda do Nascimento Arruda (2001) descreve o momento seguinte do modernismo brasileiro, quando 
este se enraíza, envereda para muitas outras linguagens além da literatura e ganha instituições e eventos que passam a dar suporte à sua difusão ampliada, como o MAM e a Bienal de São Paulo. O primado da inovação formal e o tratamento das tensões entre o tradicional e o moderno marcaram diferentes expressões da vida cultural paulistana no período e, como tal, reatualizaram e institucionalizaram o cânone modernista da cultura em um grau sem precedentes, para além das rupturas explícitas com relação às primeiras gerações de modernistas, cujas linguagens passavam a ser vistas como rotinizadas (ARRUDA, 2001, p. 24). O elo de continuidade pode ser identificado na experimentação estética e na permanência do problema da construção nacional, em ambas as gerações, apesar da sua grande diversidade interna. Em meio aos debates sobre "realismo, figuração, abstracionismo, expressão social, nacional e internacional" (ARRUDA, 2001, p. 18), a cifra "modernista" foi adquirindo, até pelo menos as últimas décadas do século XX, um valor que nenhuma outra possuía no campo cultural brasileiro, passando a ser quase sinônimo de "alta cultura" entre nós.

Em um campo cultural marcado pela dualidade entre o erudito e o popular, cada um com sua forma e seu grau de legitimação específicos, uma outra vertente permanecia excluída das preocupações do Estado e dos intelectuais de inclinação modernista. Estamos falando daquela cultura de base urbana e comercial descrita por Cohn (1973) e Barbero (1987) como cultura de massas, que crescia vertiginosamente desde as primeiras décadas do século $X X$ no Brasil e que colocava uma outra figuração do "popular", não mais circunscrito ao rural e ao tradicional. Em torno dela foi traçada uma "linha sanitário-defensiva", como demonstra Wisnik (1982), tratando especificamente da música. Analisando a produção musical brasileira da primeira metade do século XX, ele aponta uma aliança entre os pólos erudito e folclorista que deixava de fora a música popular urbana comercial e a erudita europeizante, descartadas porque não passavam no teste de "autenticidade" quanto ao seu caráter nacional (WISNIK, 1982, p. 134). Desde os anos 1940, portanto, a afirmação de um 
cânone modernista de cultura veio de par com o surgimento de uma música comercial baseada nos meios de comunicação e nos filões mais afluentes do mercado, carente de legitimidade e de atenção por parte das políticas culturais estatais voltadas a uma visão essencialista de "povo", melhor representada pelo folclore.

A este respeito, é importante registrar que, na década de 1950, esta representação do "povo" sofreu uma inflexão entre os artistas e intelectuais de diferentes posições políticas e o conceito de cultura passou a ser associado também à transformação social. Essa chave de interpretação tomou corpo no âmbito do Instituto Superior de Estudos Brasileiros (ISEB), órgão formulador das principais doutrinas do governo de Juscelino Kubistchek (1956-1961). Ela influenciou de modo decisivo as gerações seguintes, em especial na atuação do Centro Popular de Cultura $(\mathrm{CPC})$, de inspiração comunista. Segundo tal visão, seria através de uma "cultura popular" e nacional que ocorreria a tomada de consciência política do povo. Mesmo após o golpe militar de 1964, quando tiveram fim as atividades destes grupos, conceitos políticos e filosóficos forjados naquela época encontraram popularidade nos setores de esquerda (ORTIZ, 2006).

Existia, portanto, uma tensão entre passado e futuro na maneira como os produtores e gestores concebiam a cultura popular. Marcelo Ridenti (2005) identifica a raiz desta tensão no caráter "romântico-revolucionário" da estrutura de sentimentos que caracterizava artistas e intelectuais brasileiros até, pelo menos, a década de 1970. Presente em posições à esquerda e à direita do espectro político, esta estrutura de sentimentos ditava a preocupação em buscar no "povo" a matéria-prima para uma construção nacional que podia ser concebida tanto em termos conservadores quanto progressistas (RIDENTI, 2005, p. 237). Entretanto, em nenhuma destas perspectivas eram respaldadas as produções que já integravam as linguagens e conteúdos populares à lógica do mercado mais afluente. Neste sentido, "popular" referia-se ainda a uma visão tradicionalista de povo.

Talvez por isso a sociologia brasileira tenha demorado tanto a tratar da cultura popular urbana de base comercial, só despertando 
depois que ela passou a ser produzida por uma indústria cultural mais racionalizada e integrada nacionalmente, nas décadas de 1960 e 1970, sob a tutela do Regime Militar. Segundo Ortiz (1988, p. 15), até então, a temática da "cultura de massas" era ofuscada por aquelas da cultura popular e da identidade brasileira. O problema da formação nacional, deste modo, se desdobrava na busca por uma identidade mais facilmente localizável nas culturas eruditas, de matriz modernista, e popular, sob uma concepção folclorista. Mas isso significava deixar de lado o fato de que a indústria cultural começava a remodelar profundamente o contexto no qual ambos os tipos de produção cultural passaram a existir.

Somente a partir da década de 1970, surgiu na USP um conjunto de estudos que tentavam dar conta das transformações trazidas pela consolidação de uma indústria cultural no país, na esteira da tese de doutoramento de Gabriel Cohn (1973) ${ }^{1}$. Mas seus autores foram migrando para outros temas e a sociologia da cultura brasileira seguiu priorizando intelectuais e artistas situados fora do campo da indústria cultural.

O problema é que, desde pelo menos a década de 1980, surgiram indícios de mudanças significativas no campo cultural brasileiro, notadamente o desgaste de um cânone modernista e a legitimação crescente de formas de produção mais próximas às linguagens e aos formatos da indústria cultural. O quadro mais geral destas mudanças talvez possa ser descrito como a consolidação do pós-modernismo no Brasil, a partir das contribuições de Fredric Jameson. Segundo este autor, menos do que um estilo ou um conjunto de estilos dominantes nos diferentes ramos da cultura,

\footnotetext{
${ }^{1}$ É conhecida a iniciativa anterior de Luiz Costa Lima (1978) para a divulgação no Brasil de teóricos que abordaram a comunicação. Mas ela parece ter um caráter mais acidental quando contrastada com a produção uspiana sobre o tema, bem mais ampla e longeva. Destacam-se, nesta produção, os trabalhos de Maria Arminda do Nascimento Arruda, Gisela Taschner, Waldenyr Caldas, Ciro Marcondes Filho e Orlando Pinto Miranda, muitos dos quais lastrearam a análise mais geral que Renato Ortiz apresentou sobre a consolidação da indústria cultural no Brasil em "A moderna tradição brasileira".
} 
o pós-modernismo é "a lógica cultural do capitalismo tardio" (1996). Neste sentido, o termo "pós-modernismo" descreve o momento em que os antigos enclaves modernistas são penetrados definitivamente pelas formas e linguagens oriundas da indústria cultural, sendo, assim, integrados também à lógica mais geral de produção de mercadorias do ponto de vista da constituição mesma das obras, e não somente da sua circulação através do mercado. É importante lembrar que o modernismo não esteve isolado dos meios de comunicação e muito menos, do mercado, inclusive com repercussões importantes no plano formal, como demonstrou Miceli (2003) em relação à primeira geração de pintores modernistas no Brasil. Mas sua institucionalização tanto nos países centrais quanto aqui ignorou esse contato e demarcou limites bastante estreitos entre a "alta" e a "baixa" culturas, limites estes que a lógica cultural do capitalismo tardio torna problemáticos. Como explica Hyussen:

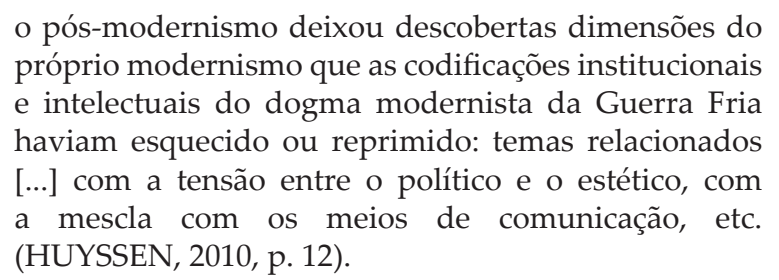

Então, para além de uma dualidade simplificadora entre o modernismo e o pós-modernismo já criticada por Huyssen (2002), o recurso a este como lógica cultural do capitalismo tardio pode nos ajudar a contrastar diferentes momentos da cultura brasileira nos quais o estatuto do cânone modernista que predomina no campo cultural tem graus de legitimidade variáveis.

Uma questão importante é a de saber em que medida, no contexto atual, a dinâmica do campo cultural descrita por Bourdieu (1982) se verifica, notadamente no que diz respeito à subordinação inconteste do campo da indústria cultural ao campo da produção erudita. Segundo aquele autor, a indústria cultural tende a vulgarizar as obras eruditas e, no momento mesmo em que 
| 54 |

Notas sobre a dualidade entre...

as tendências estéticas migram de um campo a outro, perdem seu valor como signos distintivos. Ele diz:

Verifica-se que o sistema da indústria cultural tende a realizar em bases explícitas as operações segundo as quais sempre se elaborou o que se denomina de arte popular (sistema de bens culturais consumidos pelas classes populares nas sociedades estratificadas do ocidente europeu) e que não passa, no essencial, de uma arte erudita de uma época anterior, sistematicamente reinterpretada em função de um tipo determinado de uso social. (BOURDIEU, 1982, p. 142).

Apesar de matizar essa posição no mesmo texto, reconhecendo que a cultura popular é mais próxima da "arte média" produzida pela indústria cultural pelo critério da maior acessibilidade, Bourdieu (1982, p. 142) reafirma que aquela arte é um substituto degradado e desclassificado da cultura legítima. Portanto, a teoria bourdieusiana do campo cultural supõe a existência de instrumentos muito eficazes de preservação do monopólio da legitimidade cultural pelos dominantes no interior do campo da produção erudita e por este campo no confronto com a indústria cultural. Não é de hoje que o caso brasileiro coloca alguns problemas para esta teorização. Aqui, como mostrou Sérgio Miceli (1982; 1984), os meios de comunicação tiveram um papel decisivo para a unificação do mercado de bens simbólicos e a disseminação de um arbitrário cultural dominante, uma vez que historicamente ocuparam um vácuo deixado pela ausência de um sistema de ensino universal e de qualidade, a quem caberia disseminar o reconhecimento daquele arbitrário entre as classes mais baixas. No momento de consolidação de uma indústria cultural brasileira, o déficit de escolarização de uma grande parcela da população impedia um maior aproveitamento da produção erudita pelo projeto de imposição "pedagógica" da cultura dominante (MICELI, 1982, p. 184). Este projeto encontrou na indústria cultural um suporte muito mais adequado, na medida em que pode atuar em larga escala, já que, para tanto, não demanda 
uma generalização do acesso à escola de qualidade. Nas palavras de Miceli:

os meios de comunicação de massa constituem, no interior de uma formação social como a brasileira, cujo mercado material e simbólico não se encontra unificado, os instrumentos estratégicos a serviço de uma segunda ação pedagógica que consiste em ressocializar amplos contingentes pela imposição de um habitus de classe 'dominante'. (MICELI, 1982, p. 213).

Tratando de um contexto particular, mostrei como a publicidade atuou no sentido de representar esse habitus de classe sobretudo em termos de padrões de consumo, conformando uma situação em que a superioridade das classes dominantes, mesmo do ponto de vista simbólico, tende a se expressar mais em termos de acesso a bens e serviços mais caros do que na demonstração de um gosto erudito, para muitos, sequer reconhecível como tal (ROCHA, 2002). Apesar desta ressalva, a formação do campo cultural e a institucionalização das políticas públicas de cultura no Brasil aconteceram sob a batuta de um cânone modernista e, nestes âmbitos, sua legitimidade permaneceu inconteste até as últimas décadas do século $X X$.

Os tropicalistas, no final dos anos 1960 e começo dos anos 1970, sinalizaram os primeiros indícios de uma contestação mais aberta àquele cânone. Como frequentemente acontece no interior do campo cultural, os "recém-chegados", carentes de legitimidade, tendem a adotar uma posição ambígua em relação aos "herdeiros" (a nomenclatura, como é sabido, é de Pierre Bourdieu, 2007, p. 24). Eles precisam tentar desqualificar o capital simbólico dos atores já consagrados sem deixar de reconhecer o valor em disputa no campo, valor este que a geração anterior encarna justamente por ocupar a posição dominante. Uma saída para os pleiteantes é a tentativa de se colocarem como aqueles que recuperaram o verdadeiro significado do valor em torno do qual se dá a disputa, significado este supostamente perdido no andamento da história 
do campo. No caso dos tropicalistas, um recurso engenhoso foi a reedição do próprio conceito de antropofagia, caro aos primeiros modernistas, que pode ser definido como a visão segundo a qual a característica fundante da cultura brasileira é a sua capacidade de "digerir" as diversas matrizes culturais que participaram da formação do Brasil. No novo cenário, ele passa a significar também a possibilidade de incorporar linguagens e conteúdos provenientes de diferentes ramos da indústria cultural. Assim, ainda que continuassem focados no problema da construção nacional, os tropicalistas encontraram respostas que assimilam estéticas estrangeiras contemporâneas, a partir de então definitivamente mediadas pelo mercado mais afluente (RIDENTI, 2000, p. 274-275). Neste sentido, se contrapunham diretamente ao engessamento da identidade brasileira segundo a concepção nacional popular, e o exemplo mais evidente é a polêmica gerada pelo uso tropicalista da guitarra elétrica na música brasileira. Temos, então, um declínio da ênfase no "nacional" - e também sua ressignificação - em favor de um cosmopolitismo que entra por um mercado ampliado em que ecoam também produtos e formatos estrangeiros, já sob a rubrica da cultura pop.

A partir da década de 1980, a força da lógica mercantil e da mídia no campo cultural brasileiro é reforçada pelo surgimento de uma geração de artistas e intelectuais para os quais os formatos elinguagens da indústria cultural, especialmentea TV, sãofamiliares desde a infância. Na música, por exemplo, a forte penetração de tendências europeias e americanas visível já no Tropicalismo reverberou em outros movimentos culturais que, desde então, passaram a contar com um mercado regular e ampliado, e até mesmo com uma imprensa especializada divulgando o punk, o hip-hop e vertentes da cultura pop.

Enquanto as gerações modernistas de meados do século XX compreendiam a cultura como um instrumento de transformação social e de construção nacional, tomando para tanto, a cultura popular e o mundo rural como referências primeiras, via de regra, as novas gerações de produtores culturais já têm nas linguagens e formatos da indústria cultural um parâmetro incontornável. 
A biografia muito particular de um desses produtores, o diretor de TV e de cinema Guel Arraes, pode ilustrar essa passagem. Ele dirige um núcleo no interior da Rede Globo que atua como um espaço de troca entre a emissora, carente de legitimidade diante da pressão da opinião pública e do aumento da concorrência, e uma geração de artistas vindos do vídeo independente, do jornalismo "nanico" e do teatro cômico dos anos 1980 (FECHINE, 2008). Se a "estrutura de sentimentos" é a partilha de crenças e sensibilidades que atuam como mediação entre a experiência histórica comum e a produção artística e intelectual, a dessa nova geração parece emergir de um diálogo mais intenso com a cultura pop, da desconfiança em relação à apropriação autoritária do nacionalpopular pelo Regime Militar, da recusa do partidarismo e de uma compreensão estritamente classista da política, da influência de uma concepção mais psicanalítica e contracultural de liberdade. Mas, no caso dos artistas agrupados em torno de Guel Arraes, ela recupera dois elementos importantes do modernismo, pelo menos em suas pretensões: a busca pela inovação de linguagem e pela representação dos segmentos oprimidos da sociedade. Esses elementos, especialmente o primeiro, são a base para a reivindicação de uma legitimidade cultural que extrapola o âmbito da TV e, pelo menos no campo do cinema, se contrapõe explicitamente ao cânone "cinema-novista" (consagrado na década de 1960, na esteira da produção de Glauber Rocha).

Uma questão fundamental é saber até que ponto se trata de um veio que, por estar amparado na indústria cultural, alcança grande visibilidade, mas pouca consagração na esfera de produção erudita ou se, a partir dessa visibilidade, consegue ampliar os critérios de legitimidade cultural em todos os âmbitos. Ao contrário do que possa parecer, a resposta não é simples. No caso dos produtores que se agrupam em torno de Guel Arraes, um dos seus temas preferenciais, a periferia, acabou virando objeto de uma grande exposição realizada no Rio de Janeiro em 2005. Uma de suas idealizadoras, a pesquisadora Heloísa Buarque de Holanda, a definiu como "uma exposição sobre a visualidade e a linguagem cultural da periferia do Rio de Janeiro, retratando sua maneira 
$|58|$

Notas sobre a dualidade entre...

de captar o mundo da mídia e da moda de forma antropofágica, transformadora e criativa, dentro de sua realidade econômica" ${ }^{\prime 2}$. Indo além, ela afirma:
é inquestionável a importância dessas expressões culturais no conjunto da diversidade que nos caracteriza. Não podemos definir identidade cultural nacional, simplesmente porque ela não existe no singular. Nossa cultura é plural e as estéticas centrais e periféricas, como o tecnobrega de Belém, o funk carioca ou o hip hop paulistano, compõem essa multiplicidade, sendo cada vez mais reconhecidas, também por isso. ${ }^{3}$

A referência à antropofagia e à identidade nacional, agora, no plural, indica que, mais do que a renúncia à antiga forma de consagração, temos aqui o aumento da disputa em torno do poder de definir os critérios de legitimidade cultural, e o fato de que a visibilidade midiática passa a contar como um recurso importante nessa disputa - como, de resto, tem contado nas disputas do campo político, religioso etc. Além disso, esse caso sugere também a projeção desta disputa no âmbito acadêmico, uma vez que a contestação ao cânone modernista empreendida por produtores culturais dentro e fora da indústria cultural recebe a chancela de pesquisadores como a própria Heloísa Buarque de Holanda e Hermano Vianna, interlocutor freqüente de Guel Arraes e um claro defensor de uma releitura do valor cultural do funk carioca.

Há sinais, portanto, de que vivemos, no Brasil, um momento de redefinição dos critérios de consagração cultural a partir das disputas entre atores situados nos diferentes ramos da produção erudita, nas vertentes mais tradicionalistas ou contemporâneas de cultura popular, nos filões mais afluentes ou limitados do mercado. Neste cenário, pelo menos durante o governo Lula,

\footnotetext{
${ }^{2}$ Em entrevista disponível no site www.heloisabuarquedeholanda.com.br, consultado em 02 de junho de 2011.

${ }^{3}$ Heloísa Buarque de Holanda, op. cit.
} 
o Estado atuou em favor do enfraquecimento de uma concepção modernista de cultura como belas-artes e do fortalecimento de uma noção ampliada que contempla não apenas as produções mais tradicionais da cultura popular, mas aquelas que se utilizam de linguagens e influências mais contemporâneas. Sendo assim, a "expansão" do conceito de cultura defendida pelo ministro Gilberto Gil significa também uma transformação nas obrigações e estratégias possíveis do Estado na área da cultura. Uma política cultural que abarque a dimensão "antropológica" proposta nos governos Lula depara-se com a dificuldade de estabelecer critérios que permitam especificar as produções merecedoras de financiamento por parte do Estado. A dilatação do conceito de cultura, ao mesmo tempo em que torna possível uma mudança do ponto de vista da desigualdade na produção, distribuição e acesso aos bens culturais, é um grande desafio para qualquer política cultural, pois, abarcando a total produção simbólica dos seres humanos, o conceito antropológico de cultura como um "modo de vida" desenha um limite impossível para a intervenção. Segundo Isaura Botelho, é necessário reconhecer que "uma política cultural que defina seu universo a partir do pressuposto de que 'cultura é tudo' não consegue traduzir a amplitude desse discurso em mecanismos eficazes que viabilizem sua prática" (BOTELHO, 2001, p. 75).

Sem oferecer critérios para a hierarquização das demandas dos diferentes atores sociais, as políticas culturais baseadas em uma concepção "antropológica" de cultura podem acabar sobrepondo esforços em relação à produção que o próprio mercado pode sustentar. No contexto atual, gestores preocupados em ampliar o espaço para a produção e consumo de bens simbólicos alternativos em relação à indústria cultural tem que se haver com a sua força na disseminação de gostos e hábitos. Além disso, não podem ficar indiferentes à visibilidade midiática de artistas, seja na concessão de incentivos fiscais, seja na consagração propriamente cultural. Em junho de 2009, um embate entre Caetano Veloso e o Ministério da Cultura terminou com a autorização do uso da Lei Rouanet para financiar o show do cantor. Em princípio, essa autorização havia 
$|60|$

Notas sobre a dualidade entre...

sido recusada a pretexto de ser ele um artista comercialmente viável. O então ministro Juca Ferreira voltou atrás e lembrou que a Lei Rouanet não prevê esse tipo de restrição e que até outros cantores de maior público já haviam sido beneficiados (Folha de São Paulo. Ilustrada, 23/06/2009). A resposta para este impasse, como não poderia deixar de ser, tem sido política. Tais limites não se definem a priori, mas a partir das disputas entre os diferentes atores que interpelam o Estado em busca de reconhecimento e recursos. Neste sentido, o enfraquecimento de uma visão mais polarizada e dual da cultura parece favorecer aqueles cuja produção simbólica é mais distante do cânone modernista.

\section{Bibliografia}

ARRUDA, Maria Arminda do Nascimento. Metrópole e Cultura. São Paulo no meio século XX. São Paulo: Edusc, 2001.

. "Sociologia da Cultura e Sociologia da Comunicação de Massa: esboço de uma problemática". In: MARTINS, Carlos Benedito; MARTINS, Heloisa Helena T. de Souza. (Org.). Horizontes das Ciências Sociais no Brasil: Sociologia. São Paulo: Editora Barcarolla Ltda, 2010. pp. 253-277.

BAKHTIN, Mikhail. A cultura popular na Idade Média e no Renascimento: o contexto de François Rabelais. São Paulo/ Brasília: Hucitec/Editora Universidade de Brasília, 2008.

BARBERO, Jesús Martin. De los Medios a las Mediaciones Comunicación, Cultura y Hegemonía. Barcelona: Editorial Gustavo Gili, 1987.

BOSI, Alfredo. História concisa da literatura brasileira. São Paulo: Cultrix, 1982.

BOTELHO, Isaura. "Dimensões da cultura e políticas públicas" In: São Paulo em Perspectiva. 15(2): 73-83, São Paulo, 2007. 
BOURDIEU, Pierre. “O mercado dos bens simbólicos”. In: MICELI, Sérgio (org.). A economia das trocas simbólicas. São Paulo: Perspectiva, 1982.

A distinção - crítica social do julgamento. São Paulo: Edusp; Porto Alegre: Zouk, 2007.

BUARQUE DE HOLLANDA, Heloísa. Asdrúbal trouxe o trombone. Rio de Janeiro: Aeroplano, 2004.

CANDIDO, Antonio. Literatura e sociedade: estudos de teoria e história literária. São Paulo, Nacional, 1965.

Formação da Literatura Brasileira: momentos decisivos. 6 ed. Belo Horizonte: edições Itatiaia, 1981. [1 ed. 1975].

COHN, Gabriel. Sociologia da Comunicação - teoria e ideologia. São Paulo: Pioneira, 1973.

CRANE, Diane. "High culture vesus popular culture revisited: a reconceptualization of recorded cultures". In: LAMONT, Michelle; FOURNIER, Marcel (Eds.). Cultivating differences: symbolic boundaries and the making of inequalities. Chicago: Chicago University Press, 1992.

FECHINE, Y. "Núcleo Guel Arraes: formação, influências e contribuições para uma TV de qualidade no Brasil". In: FECHINE, Yvana; FIGUEROA, Alexandre (editores). Guel Arraes - um inventor no audiovisual brasileiro. Recife: CEPE, 2008.

FURTADO, Celso. "Reflexões sobre a cultura brasileira". In: Cultura e desenvolvimento em época de crise. Rio: Paz e Terra, 1984.

GINZBURG, Carlo. O Queijo e os Vermes: o Cotidiano e as Idéias de um Moleiro Perseguido pela Inquisição. São Paulo: Companhia das Letras, 1987.

HUYSSEN, Andreas. Después de La Gran Division. Buenos Aires: Ed. Adriana Hidalgo, 2002. 
Modernismo después de la posmodernidad. Barcelona, Espanha: Gedisa, 2010.

JAMESON, Fredric. Pós-modernismo - a lógica cultural do capitalismo tardio. São Paulo, Ática, 1996.

LAFETÁ, João Luiz. 1930: A crítica e o modernismo. Prefácio de Antonio Candido. 2. ed. São Paulo: Editora 34; Duas Cidades, 2000.

LIMA, Luiz Costa. Teoria da cultura de massa. 2a. ed. (1a ed. 1970) São Paulo: Paz e Terra, 1978.

MICELI, Sérgio. A Noite da Madrinha. São Paulo: Perspectiva, 1982. . "Entre no ar em Belíndia - A Indústria Cultural Hoje". Cadernos IFCH. Campinas: UNICAMP, outubro de 1984.

- Nacional estrangeiro - História social e cultural do modernismo artístico em São Paulo. São Paulo: Companhia das Letras, 2003.

MIRANDA, Orlando Pinto. Tio Patinhas e os mitos da comunicação. Dissertação de Mestrado em Ciência Social. São Paulo: Universidade de São Paulo, 1975.

ORTIZ, Renato. A moderna tradição brasileira. São Paulo: Brasiliense, 1988.

Cultura brasileira e identidade nacional. São Paulo, Brasiliense, 2006.

RIDENTI, Marcelo. Em busca do povo brasileiro - artistas da revolução, do CPC à era da TV. Record, Rio de Janeiro, 2000.

. "Artistas e intelectuais no Brasil pós 1960". In Revista Tempo Social, vol. 17, n. 1, São Paulo: USP, Departamento de Sociologia, 2005.

ROCHA, Maria Eduarda da Mota. O consumo precário: pobreza e cultura de consumo em São Miguel dos Milagres. Coleção Estudos sobre Alagoas, n. 1. Maceió: Edufal, 2002. 
"Guel Arraes: leitura social de uma biografia". In FECHINE, Yvana; FIGUEROA, Alexandre (editores). Guel Arraes - um inventor no audiovisual brasileiro. Recife: CEPE, 2008.

TASCHNER, Gisela. Do jornalismo político à indústria cultural. Mestrado em Ciência Social. São Paulo: Universidade de São Paulo, 1978.

VIANNA, Hermano. O baile funk carioca. Dissertação de mestrado. Rio de Janeiro: PPGAS (Museu Nacional), 1987.

YÚDICE, George. A conveniência da cultura - usos da cultura na era global. Belo Horizonte: Editora da UFMG, 2004.

WILLIAMS, Raymond. Marxismo e literatura. Barcelona: Ediciones Peninsula, 2000.

WISNIK, José Miguel. O nacional e o popular na cultura brasileira música. São Paulo: Brasiliense, 1982. 